\title{
STUDIES IN POPULAR CULTURE
}

There has in recent years been an explosion of interest in culture and cultural studies. The impetus has come from two directions and out of two different traditions. On the one hand, cultural history has grown out of social history to become a distinct and identifiable school of historical investigation. On the other hand, cultural studies has grown out of English literature and has concerned itself to a large extent with contemporary issues. Neverthe less, there is a shared project, its aim, to elucidate the meanings and values implicit and explicit in the art, literature, learning, institutions and everyday behaviour within a given society. Both the cultural historian and the cultural studies scholar seek to explore the ways in which a culture is imagined, represented and received, how it interacts with social processes, how it contributes to individual and collective identities and world views, to stability and change, to social, political and economic activities and programmes. This series aims to provide an arena for the cross-fertilisation of the discipline, so that the work of the cultural historian can take advantage of the most useful and illuminating of the theoretical developments and the cultural studies scholars can extend the purely historical underpinnings of their investigations. The ultimate objective of the series is to provide a range of books which will explain in a readable and accessible way where we are now socially and culturally and how we got to where we are. This should enable people to be better informed, promote an interdisciplinary approach to cultural issues and encourage deeper thought about the issues, attitudes and institutions of popular culture.

\section{Jeffrey Richards}

